\title{
Modelo neuro-fuzzy para predição do aporte de energia de diferentes dosagens de concreto em edificações
}

\author{
Neuro-fuzzy model for energy prediction of different \\ concrete dosages in buildings
}

\section{Régis Marciano de Souza \\ Ricardo Rodrigues Magalhães Alessandro Torres Campos}

\section{Resumo}

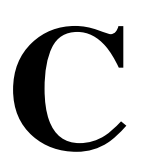

om o aumento do processo de urbanização e da população das cidades, surge a necessidade de entender o custo energético para produção dos materiais de construção. Entre os instrumentos utilizados, o aporte de energia é um importante instrumento no monitoramento do uso de fontes de energia não renováveis para produção de concretos convencionais, o que demanda novas pesquisas na área. Neste trabalho, um modelo híbrido ANFIS (Adaptive Neuro-Fuzzy Inference System) foi desenvolvido para predição do aporte de energia, para a avaliação da demanda de energia necessária para cada um dos componentes na produção de concretos convencionais (cimento, água, agregado miúdo e agregado graúdo), mediante a utilização de 101 dosagens experimentais, 101 dosagens para validação e coeficientes energéticos disponíveis em literaturas. Identificou-se que a escolha adequada da dosagem pode gerar uma economia no custo energético para produção do concreto da ordem de $24,77 \%$, mantendo a característica mecânica de resistência à compressão para construções convencionais.

Palavras-chave: Consumo de energia. Sistema ANFIS. Previsão do uso de energia na construção. Energia incorporada. Eficiência energética.

${ }^{1}$ Régis Marciano de Souza ${ }^{1}$ Instituto Federal de Educacão, Ciência e Tecnologia do Sul de Minas Pouso Alegre - MG -Brasil

${ }^{2}$ Ricardo Rodrigues Magalhães 2Universidade Federal de Lavras Lavras - MG - Brasil

${ }^{3}$ Alessandro Torres Campos 3Universidade Federal de Lavras Lavras - MG - Brasil

Recebido em 04/12/19 Aceito em 23/05/20

\begin{abstract}
An increasing process of urbanisation and a growing urban population

heighten the need to understand the energy costs of the production of building materials. One of the most important tools applied to monitor the use of nonrenewable energy resources in the production of conventional concretes is energy input, into which further research is needed. In this study, an ANFIS (adaptive neuro-fuzzy inference system) hybrid model was developed to predict energy input in order to evaluate the energy demand required for each component of the production of conventional concrete (cement, water, fine aggregate and coarse aggregate) using 101 experimental dosages, 101 validation dosages and energy coefficients available in literature. The results showed that an adequate dosage can generate energy cost savings of $24.77 \%$ in the production of concrete, while still maintaining the mechanical characteristics of compressive strength for conventional constructions.
\end{abstract}

Keywords: Energy consumption. ANFIS system. Building energy use prediction. Embodied energy. Energy efficiency. 


\section{Introdução}

O desempenho energético das estruturas de concreto, sujeita a múltiplos carregamentos, têm sido objeto de estudo desde que se introduziu o concreto como um dos principais materiais da construção civil. Para De Souza, Magalhães e De Andrade (2019), no Brasil, como em muitos outros países, o concreto tem um papel importante na construção, sendo o principal e mais consumido material de construção no mundo. As construções em concreto desempenham uma importante função na sustentabilidade das cidades. Como o concreto é um material muito empregado em edificações, fica evidente que a demanda de energia no processo de produção desse material pode ser elevada.

Para Campos et al. (2003), o estudo do fluxo de energia é uma forma de mensurar a sustentabilidade e a eficiência de agroecossistemas, e possibilita a determinação detalhada da energia envolvida na obtenção de materiais, equipamentos e processos, apontando os elementos de maior aporte e propondo opções ambientalmente menos impactantes. A origem dos materiais ou matérias-primas empregados em uma construção é um dos principais fatores que influenciam seu custo energético.

O concreto é um material composto de agregado graúdo, agregado miúdo, cimento e água, podendo ainda conter adições minerais e aditivos químicos. É notório que o quantitativo dos componentes empregados na fabricação do concreto apresenta relevante contribuição para o projeto de edificações ambientalmente sustentáveis. Zhang e Wang (2016) identificaram a tendência geral de aumento da demanda de energia empregada na produção de construções civis e rurais, e afirmaram que a demanda de energia durante a etapa da construção corresponde a mais de $60 \%$ da energia empregada no ciclo de vida do setor da construção civil.

Para Gong et al. (2012), projetar estruturas sustentáveis para economizar recursos e reduzir o impacto ambiental durante o ciclo de vida (fabricação, planejamento, projeto, construção, operação, manutenção e descarte de materiais) é uma necessidade que demanda atenção especial, principalmente em regiões caracterizadas por rápida urbanização e industrialização. Analisando-se a demanda de energia em três edifícios construídos com diferentes materiais (concreto, aço e madeira), foram observadas características semelhantes de consumo de energia, com a demanda mais alta na fase de operação dos edifícios, seguida pela produção dos materiais incorporados. Comparando os três edifícios, o edifício em concreto obteve uma porcentagem de operação de $87 \%$, o edifício em aço ficou com $76 \%$, e o construído em madeira ficou com $71 \%$ do ciclo de vida, evidenciado a necessidade de um estudo para minimizar o impacto ambiental das construções em concreto armado.

Santos (2019), ao comparar dois tipos de sistemas de laje (maciça e steel deck) a partir de suas energias incorporadas na fase de pré-uso, concluiu que os sistemas diferiram em relação à energia incorporada na faixa dos 13\%, mostrando que a energia incorporada da laje steel deck foi superior à maciça devido ao fato de o aço apresentar elevado grau de energia para sua extração e produção. De acordo com Mattioli et al. (2018), na construção de galpão para frangos de corte com modelo Darkhouse, o cimento apresentou a demanda de $8,47 \%$ do total de energia empregada na construção, sendo o segundo material de construção com maior aporte energético, perdendo lugar apenas para o aço.

Ainda, segundo Borges et al. (2014), existem tecnologias amplamente difundidas que buscam a redução do consumo de energia e de emissões durante o processo produtivo do cimento, uma delas, a utilização de equipamentos que demandam menos energia elétrica, tais como os moinhos verticais de cimento; outra, talvez a mais antiga, conhecida e difundida, o emprego de adições minerais na produção dos cimentos compostos. Na produção do concreto tradicional, o maior consumo de energia ocorre durante a produção de cimento Portland; cerca de 1.550 MJ de um total de 1.794 MJ são consumidos nesse processo, sendo grande parte dessa energia destinada à demanda térmica no processo de clinquerização.

A pesquisa nesse campo é muito pertinente no momento, diante do aumento da população e do processo de urbanização. De acordo com Deb et al. (2017), diferentes técnicas estão sendo aplicadas para predição do consumo de energia em construções. Com o intuito de compreender as formas de avaliar o consumo de energia em edifícios, Amasyali e El-Gohary (2018) apresentaram uma revisão dos estudos que desenvolveram modelos de previsão de consumo de energia de construção orientados a dados, com foco especial na revisão dos escopos de previsão, nas propriedades dos dados e nos métodos de préprocessamento de dados utilizados, nos machine learning algorithms utilizados para previsão e nas medidas de desempenho usadas para avaliação dos resultados.

Shaikh et al. (2014) apresentaram uma pesquisa abrangente e significativa realizada em sistemas de controle inteligentes de ponta para gerenciamento de energia e conforto em edifícios, visando fornecer melhor 
compreensão e um conhecimento atualizado sobre tendências relacionadas a parâmetros de conforto, sistemas de controle, métodos computacionais inteligentes, ferramentas de simulação, comportamento e preferências dos ocupantes, tipos de construção, considerações sobre fontes de suprimento e interesse de pesquisa dos países nesse setor.

Naji et al. (2016) utilizaram o ANFIS (Adaptive Neuro-Fuzzy Inference System) para estimar o consumo de energia dos edifícios, com 180 simulações para diferentes valores de espessura do material e condutividade térmica do material de isolamento, por meio do software EnergyPlus. Os resultados obtidos foram mais confiáveis e precisos que os resultados por meio de ANN (Artificial Neural Network) e GP (Genetic Programming).

Mousavi-Avval et al. (2017) afirmaram que o ANFIS pode ser uma ferramenta útil para prever os índices energéticos, econômicos e ambientais dos sistemas de produção agrícola. Essa informação foi ratificada por Nabavi-Pelesaraei et al. (2018), que alegaram que o modelo de predição por ANFIS é o modelo mais indicado quando comparado com $\mathrm{ANN}$, devido à maior velocidade computacional e a sua alta precisão, podendo ser utilizado para avaliar o fluxo de energia e os indicadores ambientais, e para o gerenciamento da tomada de decisões na produção de arroz. Outros trabalhos alcançaram bons resultados ao utilizar o ANFIS em problemas físicos de engenharia referentes à eficiência energética, entre eles os de Li, Su e Chu (2011), Al-Ghandoor (2013), Olatomiwa et al. (2015) e Shamshirband et al. (2015).

Além das características energéticas dos componentes de um concreto, é importante correlacionar o desempenho sustentável com a eficiência em relação às características físicas dos concretos fresco e endurecido, características essas essenciais em estruturas de concreto armado. Diferentes fatores diretos e indiretos podem influenciar no fluxo de energia, nas características físicas, químicas e mecânicas de concretos de diferentes dosagens. De acordo com Mehta e Monteiro (2014), a resistência mecânica à compressão e a trabalhabilidade do concreto no estado fresco podem ter suas características físicas, químicas e mecânicas alteradas em função das características dos componentes (agregado miúdo, agregado graúdo, água e cimento) e do quantitativo desses componentes na produção de concretos convencionais.

Como o concreto é um material com uma energia incorporada relativamente alta, é adequado um estudo da interação entre o quantitativo dos componentes empregados e sua relação com a eficiência energética de edificações. Este trabalho propõe o uso do sistema ANFIS como forma alternativa para predição de dosagens de concreto com menor impacto na demanda de energia para a construção de edificações, sem perder as características mecânicas de resistência à compressão do material e mantendo a trabalhabilidade compatível com o comportamento físico de um concreto convencional no estado fresco, por ser uma técnica que tem alcançado bons resultados em predições de cenários referentes à demanda de energia em edificações. Objetiva-se ainda interpretar o fluxo de energia no processo para diferentes dosagens e avaliar o impacto no custo energético para implantação de uma edificação em concreto armado para diferentes dosagens de concreto, no intuito de identificar correlações entre as variáveis e interpretar o fluxo energético no campo das dosagens de concretos eficientes em relação à demanda de energia. Busca-se evidenciar novas contribuições científicas para estudo da demanda de energia no processo de fabricação do material mais utilizado na construção civil (concreto), o que vem ao encontro de pesquisas recentes sobre a avaliação do impacto ambiental em edificações, entre as quais se destacam as pesquisas de Gong et al. (2012), Deb et al. (2017), Nabavi-Pelesaraei et al. (2018), Mattioli et al. (2018) e Santos (2019).

\section{Materiais e métodos}

Foi adotada a seguinte organização neste estudo:

(a) um banco de dados foi desenvolvido, composto de 101 dados experimentais de corpos de prova, para diferentes dosagens de concreto;

(b) utilizando coeficientes energéticos de literaturas, foi determinada a energia empregada em cada uma das dosagens propostas;

(c) um modelo híbrido neuro-fuzzy (ANFIS) foi desenvolvido para predizer a demanda de energia dos diferentes cenários, atendendo ao domínio proposto para o quantitativo de cada um dos componentes das dosagens; e

(d) uma edificação-tipo foi proposta para um estudo comparativo do impacto na demanda de energia de dosagens com máxima e mínima demanda de energia, considerando intervalos predefinidos de resistência mecânica à compressão. 


\section{Características do concreto}

Com o intento de gerar um banco de dados de dosagens de concreto convencionais, para avaliação da resistência à compressão e da demanda de energia embutida, os agregados miúdos e graúdos foram caracterizados de acordo com as normas NBR NM 27 (ABNT, 2001), NBR NM 45 (ABNT, 2006), NBR NM 52 (ABNT, 2009a) e NBR NM 53 (ABNT, 2009b), conforme a Tabela 1.

A pesquisa foi realizada no município de Pouso Alegre, MG (Brasil), e foi adotada a água proveniente da rede de abastecimento público, com agregado miúdo natural e agregado graúdo formado por britagem de rochas da região, procedimento esse de acordo com Santos e Ferrari (2019), materiais representados na Figura 1(a).

Para uma efetiva avaliação quantitativa de cada componente na moldagem dos corpos de prova cilíndricos de $10 \mathrm{~cm}$ de diâmetro e $20 \mathrm{~cm}$ de altura, utilizou-se um único cimento Portland do tipo CP II E, classificado e padronizado pela norma brasileira NBR 16697 (ABNT, 2018). Todos os corpos de provas foram preparados em condições ambientais semelhantes, moldados e com adensamento manual com 2 camadas e 12 golpes por camada, utilizando-se o processo de cura por imersão em água, Figura 1(c) e 1(d), procedimentos esses estabelecidos na norma NBR 5738 (ABNT, 2015a). Durante o preparo dos corpos de prova, foi realizado também o ensaio de abatimento de tronco de cone do concreto para a avaliação da trabalhabilidade das amostras, de acordo com o estabelecido na norma NBR NM 67 (ABNT, 1998), Figura 1(b).

A resistência mecânica à compressão dos corpos de prova capeados com Neoprene foi determinada, após 28 dias de cura por imersão em água, por ensaio de compressão axial utilizando máquina universal eletrônica digital com capacidade $100 \mathrm{t}$ (hidráulica I-3058, da marca Pavitest), procedimentos de acordo com a NBR 5739 (ABNT, 2015d), Figuras 1(e) e 1(f). Esses procedimentos foram aplicados para as 101 dosagens propostas (Tabela 4), adotou-se uma amostragem com boa distribuição, e cada dosagem teve uma amostragem com representatividade quantitativa estabelecida conforme proposto pela norma NBR 12655 (ABNT, 2015c).

A definição das dosagens utilizadas nesta pesquisa teve como ponto de partida 50 dosagens preliminares desenvolvidas com uso do método ABCP (Associação Brasileira de Cimento Portland). Foram adotados intervalos para as variáveis de entrada (cimento, agregado miúdo, agregado graúdo e água) similares aos adotados por Abolpour et al. (2013), Tabela 3. Com o uso dessas dosagens preliminares e dos valores máximos e mínimos das variáveis de entrada e saída (Tabela 3), foram propostas 101 dosagens bem distribuídas entre os intervalos previstos, com o apoio do software Microsoft Excel.

\section{Análise energética da edificação}

A indústria do cimento demanda muita energia na produção do cimento Portland, sendo o cimento uma matéria-prima para a produção dos concretos em construções convencionais. Com o avanço da urbanização e com o aumento da população, diferentes trabalhos foram propostos nos últimos anos com o intuito de propor alternativas para minimizar o impacto ambiental gerado por esse aumento da demanda de energia necessária na construção, nos materiais e no ciclo de vida das edificações. Neste trabalho, para a avaliação da demanda de energia das diferentes dosagens propostas, utilizaram-se coeficientes energéticos de literatura, conforme a Tabela 2, procedimento também adotado por Santos (2019).

Para a montagem do banco de dados de demanda de energia por dosagens, cada componente constituinte das dosagens propostas foi selecionado de forma a manter a trabalhabilidade e a resistência mecânica à compressão dentro de limites (mínimos e máximos) compatíveis com valores adotados em concretos convencionais. O domínio desses componentes no campo quantitativo das dosagens foi similar aos valores adotados por Abolpour et al. (2013), conforme a Tabela 3.

Tabela 1 - Propriedades físicas dos agregados graúdos e miúdos

\begin{tabular}{l|c|c}
\hline & Agregado miúdo & Agregado graúdo \\
\hline Massa específica unitária média em kg/m & $1.600,67$ & $1.526,90$ \\
Massa específica aparente média em kg/m & $2.107,05$ & $2.673,47$ \\
\hline
\end{tabular}

298 Souza, R. M. de; Magalhães, R. R.; Campos, A. T. 
Figura 1 - Materiais empregados na produção do concreto e ensaios utilizados na avaliação dos corpos de prova
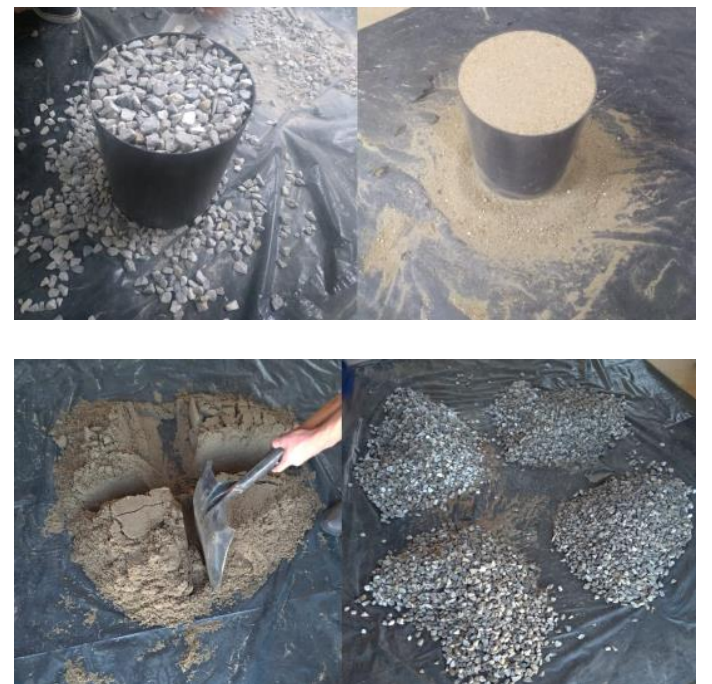

(a)

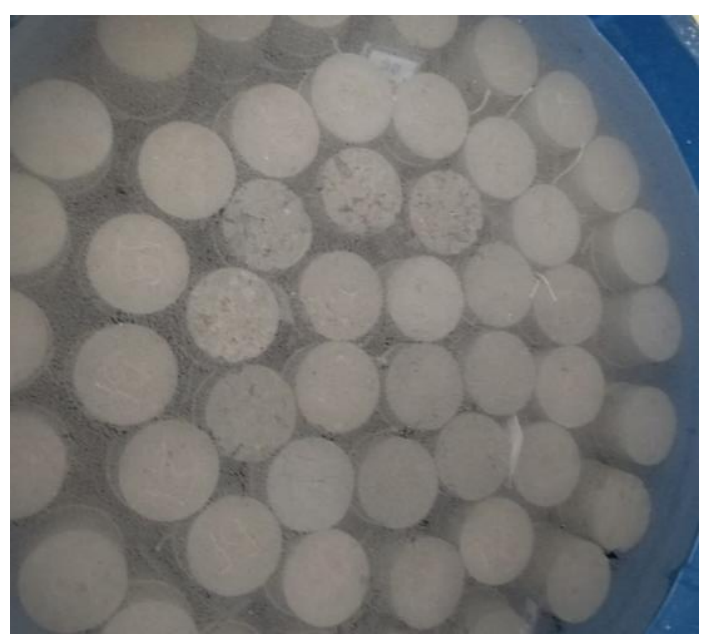

(c)

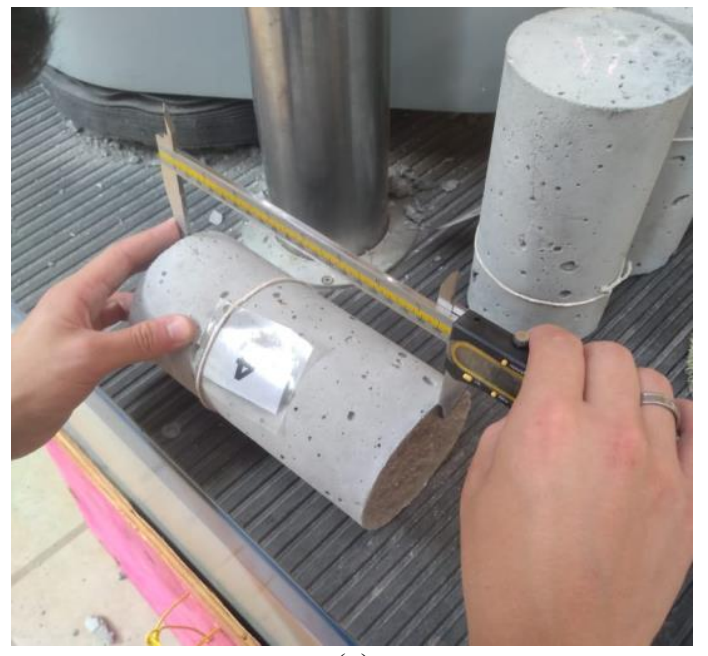

(e)

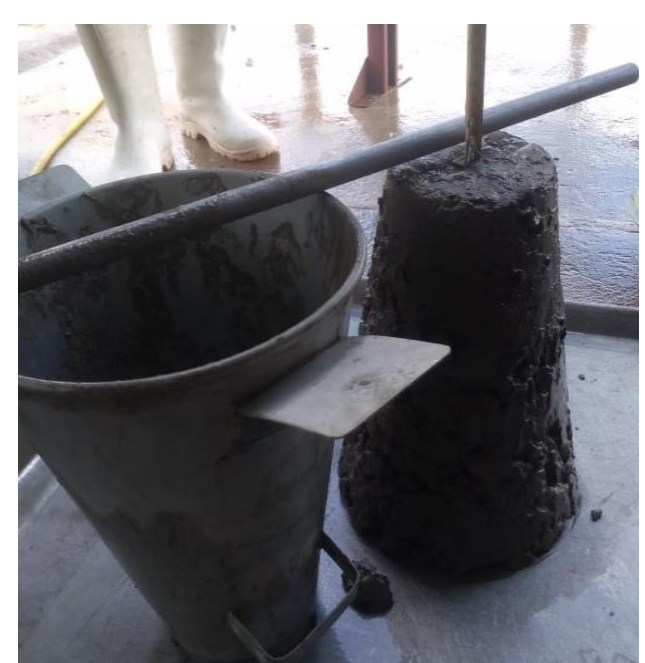

(b)

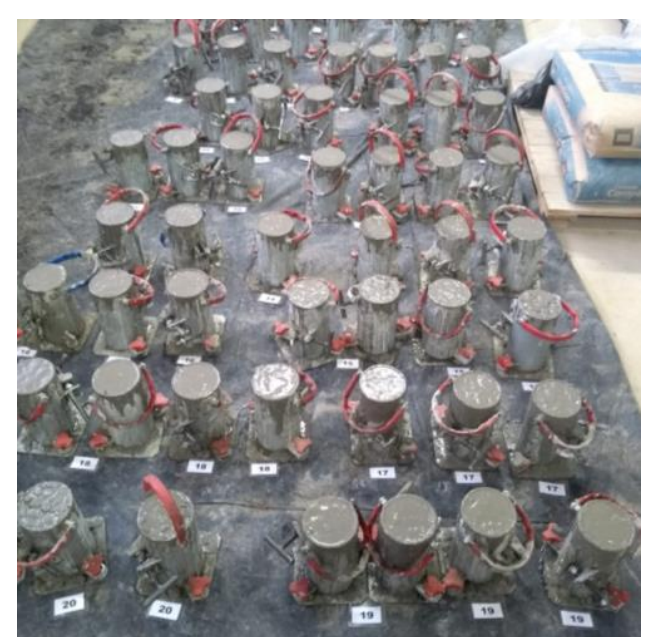

(d)

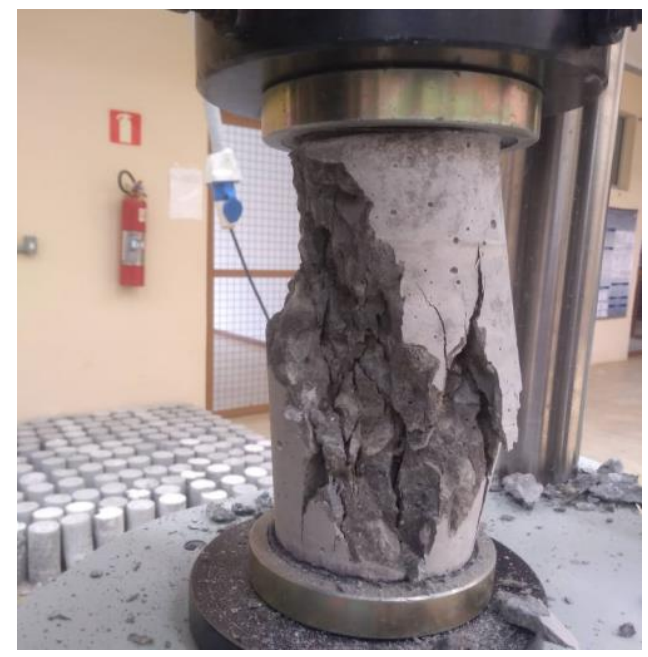

(f) 
Tabela 2 - Coeficientes energéticos dos componentes do concreto

\begin{tabular}{l|c|c}
\hline \multicolumn{1}{c|}{ Componente analisado } & Coeficiente energético & Fonte \\
\hline Cimento Portland & $4,80 \mathrm{MJ} / \mathrm{kg}$ & Mithun e Narasimhan (2015) \\
Agregado graúdo & $0,083 \mathrm{MJ} / \mathrm{kg}$ & Mithun e Narasimhan (2015) \\
Agregado miúdo & $0,081 \mathrm{MJ} / \mathrm{kg}$ & Mithun e Narasimhan (2015) \\
Água & $0,200 \mathrm{MJ} / \mathrm{kg}$ & Mithun e Narasimhan (2015) \\
\hline
\end{tabular}

Tabela 3 - Domínio dos componentes das dosagens

\begin{tabular}{|c|c|c|c|}
\hline $\begin{array}{c}\text { Cimento Portland } \\
\left(\mathrm{kg} / \mathrm{m}^{3}\right)\end{array}$ & $\begin{array}{c}\text { Água } \\
\left(\mathrm{kg} / \mathrm{m}^{3}\right)\end{array}$ & $\begin{array}{c}\text { Agregado graúdo } \\
\left(\mathrm{kg} / \mathrm{m}^{3}\right)\end{array}$ & $\begin{array}{c}\text { Agregado miúdo } \\
\left(\mathrm{kg} / \mathrm{m}^{3}\right)\end{array}$ \\
\hline \begin{tabular}{l|l} 
Mínimo & Máximo \\
\end{tabular} & \begin{tabular}{l|l} 
Mínimo & Máximo \\
\end{tabular} & \begin{tabular}{l|l} 
Mínimo & Máximo \\
\end{tabular} & \begin{tabular}{l|l} 
Mínimo & Máximo \\
\end{tabular} \\
\hline$[380-$ & {$\left[\begin{array}{lll}155 & - & 270]\end{array}\right.$} & {$[800-1.150]$} & $-735]$ \\
\hline
\end{tabular}

Figura 2 - Arquitetura do modelo ANFIS

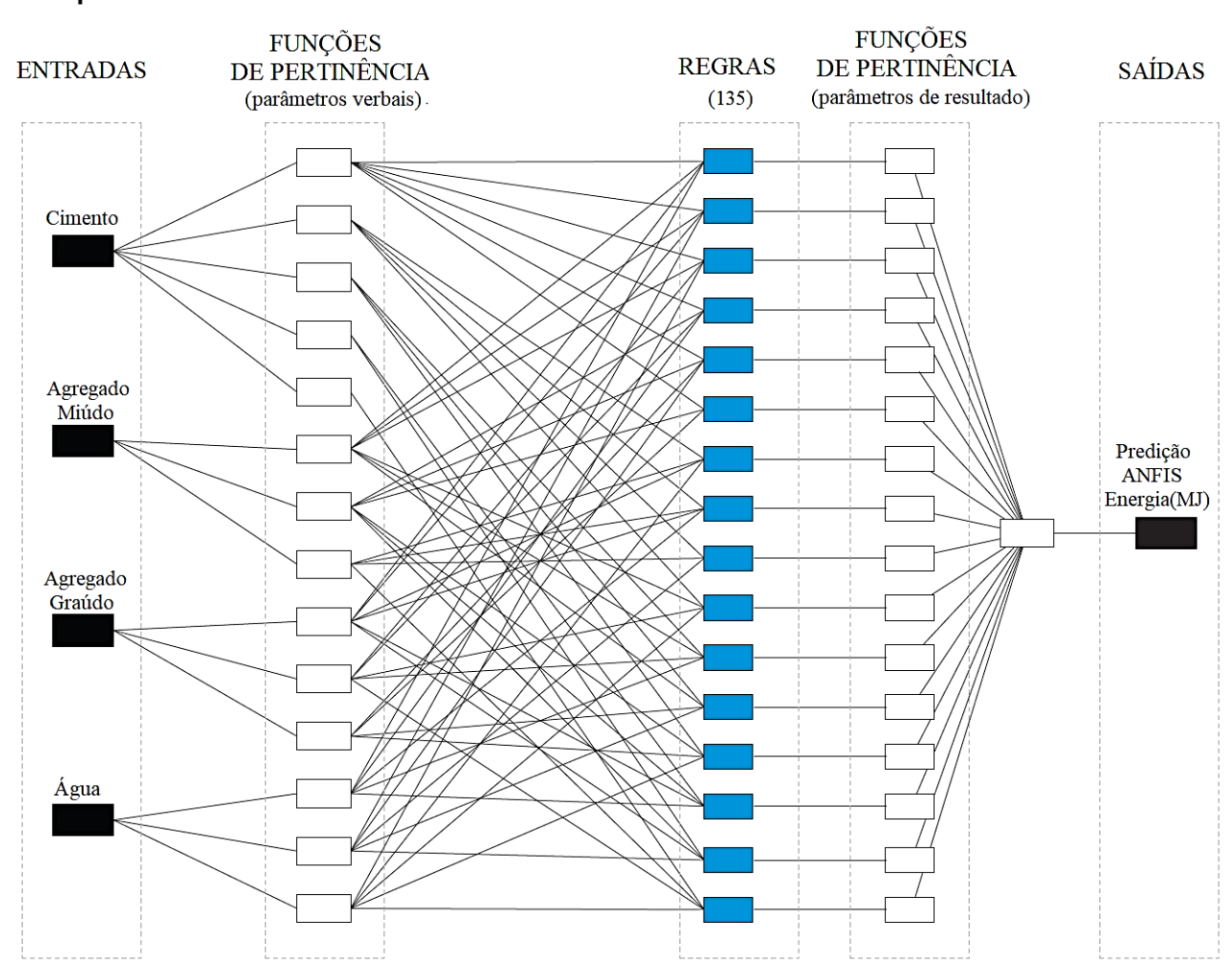

O modelo proposto por Abolpour et al. (2013) utilizou lógica fuzzy para a avaliação da resistência mecânica à compressão de concretos não convencionais, considerando como variáveis de entrada quantitativo de cimento, água, escória granulada de alto forno, cinza volante, superplastificante, agregado miúdo, agregados graúdos e idade do concreto. Neste trabalho, para o preparo das dosagens, foram considerados os componentes cimento, água, agregado graúdo e agregado miúdo, levando-se em consideração que um concreto com esses componentes foi definido como convencional por Knoeri, Sanyé-Mengual e Althaus (2013). O banco de dados adotado nesta pesquisa para a avaliação da demanda de energia total por dosagem, considerando os coeficientes energéticos da Tabela 2, está apresentado na Tabela 4.

\section{Modelo neuro-fuzzy}

Neste trabalho um modelo híbrido ANFIS foi utilizado para prever o consumo de energia na produção de concretos convencionais. Essa abordagem híbrida é mais indicada para a análise da eficiência energética (NAJI, 2016; NABAVI-PELESARAEI et al., 2018). 
O sistema híbrido proposto utiliza de RNA (Artificial Neural Networks) combinado com lógica fuzzy baseada no processo de inferência fuzzy de Takagi-Sugeno para definição das características do modelo ANFIS (Figura 2). O modelo foi treinado baseado no banco de dados mostrado na Tabela 4.

Tabela 4 - Banco de dados das dosagens

\begin{tabular}{|c|c|c|c|c|c|c|c|c|c|c|c|c|c|}
\hline \multicolumn{4}{|c|}{ Demanda de energia } & $\begin{array}{c}\text { Energia } \\
\text { total } \\
(\mathrm{MJ}) \\
\end{array}$ & $\begin{array}{c}\mathbf{f c} \\
(\mathbf{M P a})\end{array}$ & $\begin{array}{c}\text { Slump } \\
(\mathbf{m m})\end{array}$ & \multicolumn{4}{|c|}{ Demanda de energia } & $\begin{array}{c}\text { Energia } \\
\text { total } \\
(\mathrm{MJ})\end{array}$ & $\begin{array}{c}\text { fc } \\
(\mathrm{MPa})\end{array}$ & $\begin{array}{r}\text { Slump } \\
(\mathbf{m m})\end{array}$ \\
\hline $2.066,11$ & 19,58 & 77,86 & 43,00 & $2.206,55$ & 12,4 & 200 & $1.935,79$ & 45,82 & 93,87 & 44,91 & $2.120,39$ & 15,6 & 190 \\
\hline $2.769,65$ & 47,79 & 90,47 & 49,31 & $2.957,22$ & 31,5 & 140 & $1.947,94$ & 32,31 & 77,65 & 44,09 & $2.101,98$ & 12,3 & 220 \\
\hline $2.668,37$ & 55,18 & 70,38 & 50,35 & $2.844,28$ & 30,3 & 145 & $2.010,53$ & 22,48 & 85,96 & 44,03 & $2.162,99$ & 12,1 & 220 \\
\hline $2.741,71$ & 58,55 & 81,10 & 52,15 & $2.933,51$ & 29,5 & 150 & $1.876,80$ & 30,55 & 73,01 & 42,54 & $2.022,90$ & 12,3 & 215 \\
\hline $2.674,90$ & 38,39 & 72,70 & 47,05 & $2.833,04$ & 25,4 & 150 & $1.931,57$ & 53,78 & 84,31 & 47,30 & $2.116,95$ & 16,0 & 205 \\
\hline $2.762,26$ & 40,16 & 73,17 & 48,98 & $2.924,56$ & 36,6 & 135 & $1.846,18$ & 26,13 & 84,94 & 42,12 & $1.999,37$ & 12,0 & 215 \\
\hline $2.646,24$ & 18,44 & 68,55 & 42,57 & $2.775,80$ & 38,0 & 75 & $1.910,93$ & 52,69 & 76,44 & 48,02 & $2.088,08$ & 16,9 & 220 \\
\hline $2.676,00$ & 28,44 & 78,58 & 45,92 & $2.828,94$ & 32,3 & 105 & $2.484,29$ & 21,61 & 80,44 & 32,69 & $2.619,02$ & 46,8 & 10 \\
\hline $2.627,28$ & 26,58 & 94,60 & 45,15 & $2.793,61$ & 27,4 & 25 & $2.150,50$ & 35,94 & 82,45 & 34,71 & $2.303,58$ & 39,2 & 30 \\
\hline $2.552,64$ & 45,26 & 82,57 & 49,41 & $2.729,88$ & 25,1 & 150 & $2.497,68$ & 40,38 & 81,39 & 34,60 & $2.654,05$ & 51,8 & 5 \\
\hline $2.634,05$ & 17,05 & 90,89 & 44,59 & $2.786,58$ & 21,1 & 130 & $2.639,71$ & 52,60 & 94,29 & 36,16 & $2.822,76$ & 53,9 & 0 \\
\hline $2.546,16$ & 49,62 & 86,15 & 50,57 & $2.732,51$ & 23,4 & 175 & $2.606,54$ & 42,44 & 82,64 & 35,42 & $2.767,04$ & 49,3 & 0 \\
\hline $2.580,82$ & 52,09 & 85,89 & 52,38 & $2.771,17$ & 29,8 & 150 & $2.187,55$ & 37,57 & 81,26 & 34,50 & $2.340,88$ & 47,2 & 0 \\
\hline $2.517,98$ & 36,39 & 81,11 & 48,22 & $2.683,71$ & 17,9 & 170 & $2.052,96$ & 58,52 & 66,52 & 37,72 & $2.215,72$ & 42,7 & 15 \\
\hline $2.523,94$ & 40,46 & 80,18 & 49,38 & $2.693,96$ & 23,1 & 130 & $1.964,98$ & 53,69 & 81,92 & 37,48 & $2.138,07$ & 34,7 & 35 \\
\hline $2.302,80$ & 39,05 & 84,77 & 46,66 & $2.473,29$ & 20,1 & 150 & $2.392,85$ & 51,56 & 68,91 & 37,03 & $2.550,35$ & 37,9 & 65 \\
\hline $2.425,78$ & 43,67 & 90,58 & 49,98 & $2.610,01$ & 19,6 & 200 & $1.993,49$ & 46,57 & 73,65 & 36,28 & $2.149,99$ & 37,9 & 110 \\
\hline $2.411,52$ & 38,16 & 89,51 & 48,56 & $2.587,74$ & 16,4 & 185 & $2.194,75$ & 45,03 & 72,58 & 34,60 & $2.346,96$ & 50,2 & 10 \\
\hline $2.376,34$ & 45,87 & 82,29 & 49,87 & $2.554,37$ & 23,5 & 190 & $2.773,30$ & 25,25 & 71,20 & 33,49 & $2.903,23$ & 56,4 & 0 \\
\hline $2.342,64$ & 17,16 & 84,94 & 43,77 & $2.488,51$ & 15,7 & 190 & $2.077,92$ & 45,22 & 87,68 & 35,87 & $2.246,69$ & 36,5 & 20 \\
\hline $2.395,01$ & 36,41 & 75,83 & 48,99 & $2.556,25$ & 17,6 & 200 & $2.160,00$ & 32,40 & 91,30 & 48,00 & $2.331,70$ & 11,2 & 195 \\
\hline $2.331,31$ & 50,34 & 94,13 & 51,82 & $2.527,60$ & 18,0 & 150 & $2.496,00$ & 19,44 & 70,55 & 45,00 & $2.630,99$ & 16,8 & 165 \\
\hline $2.313,79$ & 30,02 & 75,02 & 47,13 & $2.465,97$ & 17,5 & 200 & $2.280,00$ & 36,45 & 68,06 & 36,00 & $2.420,51$ & 42,6 & 35 \\
\hline $2.227,68$ & 28,34 & 74,06 & 45,59 & $2.375,67$ & 14,1 & 190 & $2.064,00$ & 48,60 & 83,00 & 38,00 & $2.233,60$ & 31,9 & 10 \\
\hline $2.241,79$ & 54,03 & 92,24 & 51,57 & $2.439,62$ & 18,2 & 165 & $1.968,00$ & 28,35 & 69,31 & 50,00 & $2.115,66$ & 8,9 & 240 \\
\hline $2.286,05$ & 39,47 & 78,38 & 49,49 & $2.453,39$ & 17,5 & 215 & $2.688,00$ & 51,03 & 87,15 & 40,00 & $2.866,18$ & 46,0 & 20 \\
\hline $2.272,99$ & 20,13 & 87,68 & 45,18 & $2.425,99$ & 13,6 & 180 & $2.376,00$ & 20,25 & 70,55 & 52,00 & $2.518,80$ & 11,2 & 225 \\
\hline $2.155,39$ & 48,87 & 78,55 & 49,62 & $2.332,43$ & 17,0 & 205 & $1.968,00$ & 17,01 & 88,81 & 32,00 & $2.105,82$ & 31,3 & 0 \\
\hline $2.190,24$ & 23,60 & 75,21 & 44,78 & $2.333,83$ & 13,7 & 215 & $2.400,00$ & 56,70 & 72,63 & 40,00 & $2.569,33$ & 41,6 & 0 \\
\hline $2.116,08$ & 51,17 & 90,74 & 49,67 & $2.307,66$ & 15,3 & 165 & $2.160,00$ & 40,50 & 93,38 & 35,00 & $2.328,88$ & 36,1 & 0 \\
\hline $2.140,22$ & 51,28 & 77,14 & 50,28 & $2.318,92$ & 14,3 & 220 & $2.784,00$ & 22,68 & 76,36 & 48,00 & $2.931,04$ & 21,5 & 155 \\
\hline $2.217,36$ & 19,27 & 92,13 & 45,07 & $2.373,84$ & 13,4 & 190 & $2.640,00$ & 36,45 & 83,83 & 54,00 & $2.814,28$ & 16,4 & 215 \\
\hline $2.140,03$ & 48,19 & 81,16 & 50,39 & $2.319,78$ & 15,2 & 205 & $2.496,00$ & 25,11 & 74,70 & 46,00 & $2.641,81$ & 20,2 & 200 \\
\hline $2.072,93$ & 37,19 & 70,75 & 47,34 & $2.228,21$ & 12,2 & 220 & $1.992,00$ & 51,84 & 90,06 & 33,00 & $2.166,90$ & 28,0 & 0 \\
\hline $2.079,02$ & 40,40 & 72,62 & 48,26 & $2.240,29$ & 12,2 & 230 & $2.352,00$ & 26,73 & 67,23 & 44,00 & $2.489,96$ & 10,7 & 170 \\
\hline $2.097,26$ & 27,37 & 80,83 & 45,77 & $2.251,23$ & 12,3 & 225 & $2.448,00$ & 17,01 & 68,48 & 53,00 & $2.586,49$ & 17,0 & 245 \\
\hline $2.029,01$ & 27,32 & 88,75 & 44,49 & $2.189,58$ & 12,2 & 210 & $2.784,00$ & 52,65 & 76,36 & 34,00 & $2.947,01$ & 48,4 & 0 \\
\hline $2.091,55$ & 52,73 & 86,04 & 47,28 & $2.277,60$ & 19,7 & 175 & $2.856,00$ & 38,88 & 85,91 & 49,00 & $3.029,79$ & 29,6 & 155 \\
\hline $1.984,51$ & 21,72 & 94,29 & 41,20 & $2.141,72$ & 12,7 & 180 & $1.992,00$ & 37,26 & 68,06 & 46,00 & $2.143,32$ & 10,9 & 240 \\
\hline
\end{tabular}


No entanto, para melhorar a confiabilidade e minimizar os desvios dos dados de predição, diferentes possibilidades de modelos ANFIS foram testadas. Toda a modelagem foi realizada utilizando o software comercial MATLAB, com auxílio computacional do Fuzzy Logic Toolbox, da função ANFIS da linha de comando e do aplicativo iterativo Neuro-Fuzzy Designer.

O modelo híbrido ANFIS proposto foi preparado com 135 parâmetros lineares, 28 parâmetros não lineares e 135 regras. Na etapa de transformação os valores discretos das variáveis de entrada foram convertidos em valores difusos (fuzzification), sendo adotados cinco conjuntos fuzzy de entrada com funções de pertinência do tipo gaussiana. Para a representação da variável de entrada cimento $(\mathrm{kJ} / \mathrm{m})$ foram adotadas cinco funções de pertinência. Para a representação da variável de entrada água $(\mathrm{kJ} / \mathrm{m})$ foram adotadas três funções de pertinência.

Além disso, foram adotadas três funções de pertinência para os conjuntos fuzzy de entrada agregado miúdo $(\mathrm{kJ} / \mathrm{m})$ e agregado graúdo $(\mathrm{kJ} / \mathrm{m})$. Por fim, foi adotada a média ponderada de todas as saídas de regra, por ser o padrão para os sistemas de inferência de Takagi-Sugeno. Os procedimentos metodológicos utilizados para modelar o ANFIS proposto foram compatíveis com os métodos adotados por Li, Su e Chu (2011) e Shamshirband et al. (2015).

Buscando maior confiabilidade do modelo híbrido ANFIS, o modelo de predição foi submetido a testes de validação por meio de predições da energia para diferentes dosagens. Foram utilizadas 101 combinações de dosagens, de acordo com os limites da Tabela 3, adotando concreto com características semelhantes à proposta desta pesquisa e coeficientes energéticos da Tabela 2. Entre as dosagens utilizadas, vale destacar as que foram propostas por Hatem et al. (2012), Gupta (2015) e Ahmed et al. (2016).

\section{Característica da edificação}

Objetivando uma discussão da demanda de energia para diferentes dosagens aplicadas em uma construçãotipo, foram propostas algumas etapas:

(a) modelagem de uma construção-tipo no software Revit para determinação do volume de concreto necessário na construção (Figura 3);

(b) determinação de dosagens baseada no banco de dados (Tabela 4) em função da demanda de energia máxima e mínima para diferentes intervalos de resistência mecânica à compressão;

(c) avaliação do impacto na demanda de energia comparando as dosagens com máxima e mínima demanda de energia dentro de intervalos de resistência mecânica à compressão; e

(d) discussão e avaliação da demanda de energia necessária na construção proposta.

A construção proposta tem área interna total de 55,11 m, em concreto armado, vedação com uso de blocos não estruturais e pé-direito de 3,0 m. Para a avaliação do volume estimado de concreto necessário, foram considerados os elementos vigas, pilares, fundação do tipo radier, lajes maciças e dez por cento de perdas diversas, que podem ocorrer na etapa da construção. Portanto, para a construção da edificação proposta, considerou-se um volume aproximado de $25 \mathrm{~m}$ de concreto convencional.

Os dados de demanda de energia por dosagem foram correlacionados com a resistência mecânica à compressão (fc), na Figura 4. Para comparação das dosagens e das diferentes demandas de energia, foram avaliados limites máximos e mínimos de demanda de energia por intervalos definidos com valores de 10 $\mathrm{MPa}$ em $10 \mathrm{MPa}$ da fc.

Diante de diferentes possibilidades de combinações de componentes, foi proposto o uso de valores máximos e mínimos de energia por dosagem para cada intervalo, com valor de $10 \mathrm{MPa}$, conforme a Tabela 5. Essas dosagens foram adotadas na construção proposta no intuito de identificar a demanda de energia total para a construção proposta e qual o impacto ambiental na demanda de energia para diferentes dosagens.

\section{Resultados e discussões}

Neste item, parâmetros estatísticos e um banco de dados composto de 101 dados foram empregados na validação do modelo ANFIS. Diferentes dosagens foram analisadas para o estudo da demanda total de energia da edificação proposta, e os resultados foram discutidos com base em diferentes literaturas. 
Figura 3 - Planta baixa humanizada

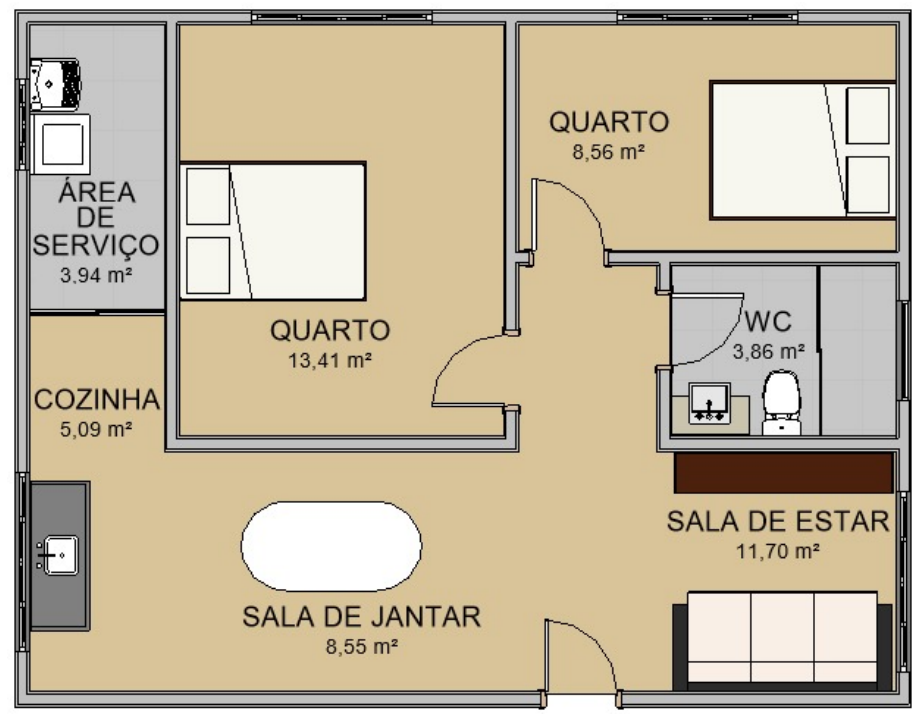

Figura 4 - Demanda de energia em função da resistência mecânica

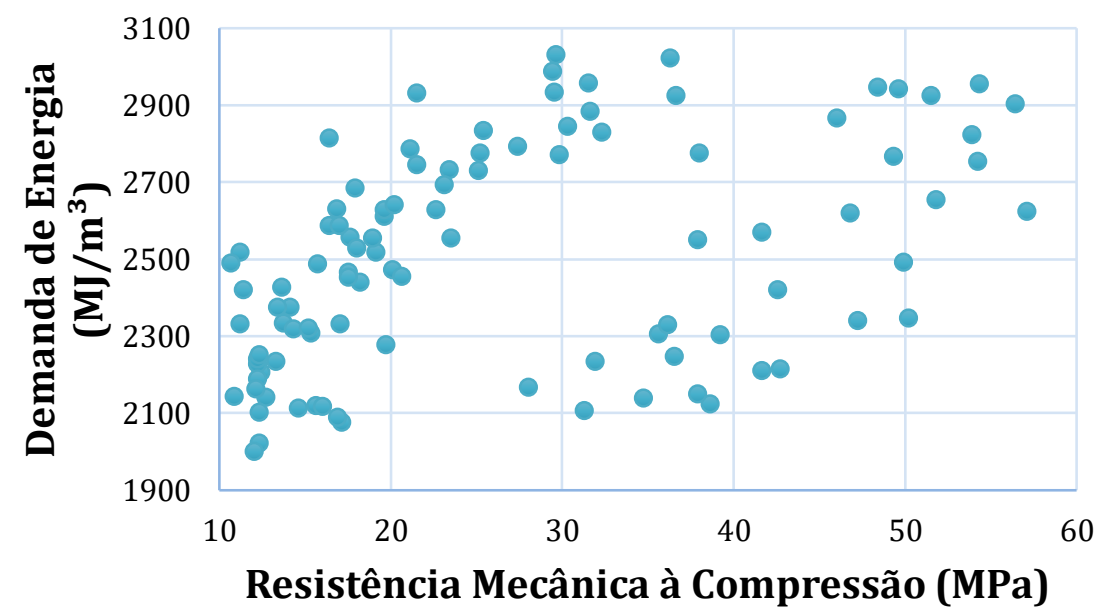

Tabela 5 - Dosagens em função da demanda máxima e mínima de energia

\begin{tabular}{|c|c|c|c|c|c|c|c|c|c|}
\hline $\begin{array}{c}\text { Dosagens } \\
\text { de } \\
\text { concreto }\end{array}$ & $\begin{array}{l}\text { Demanda } \\
\text { de energia }\end{array}$ & $\begin{array}{c}\text { Energia } \\
\text { total } \\
\left(\mathbf{M J} / \mathbf{m}^{3}\right)\end{array}$ & $\begin{array}{c}\text { Domínio } \\
\text { da } \\
\text { variável } \\
\text { fc (MPa) }\end{array}$ & $\begin{array}{c}\mathbf{f c} \\
(\mathbf{M P a})\end{array}$ & $\begin{array}{c}\text { Slump } \\
(\mathrm{mm})\end{array}$ & $\begin{array}{c}\text { Cimento } \\
\text { Portland } \\
\left(\mathrm{kg} / \mathrm{m}^{3}\right)\end{array}$ & $\begin{array}{c}\text { Água } \\
\left(\mathrm{kg} / \mathrm{m}^{3}\right)\end{array}$ & $\begin{array}{l}\text { Agregado } \\
\text { graúdo } \\
\left(\mathbf{k g} / \mathbf{m}^{3}\right)\end{array}$ & $\begin{array}{c}\text { Agregado } \\
\text { miúdo } \\
\left(\mathbf{k g} / \mathbf{m}^{3}\right)\end{array}$ \\
\hline $\bar{A}$ & Máximo & $2.814,28$ & $10-20$ & 16,4 & 215 & 550,00 & 270,00 & $1.010,00$ & 450,00 \\
\hline B & Mínimo & $1.999,37$ & $10-20$ & 12,0 & 215 & 384,62 & 210,61 & $1.023,39$ & 322,61 \\
\hline $\mathrm{C}$ & Máximo & $3.029,79$ & $20-30$ & 29,6 & 155 & 595,00 & 245,00 & $1.035,00$ & 480,00 \\
\hline D & Mínimo & $2.166,90$ & $20-30$ & 28,0 & 0 & 415,00 & 165,00 & $1.085,00$ & 640,00 \\
\hline E & Máximo & $3.022,40$ & $30-40$ & 36,3 & 145 & 597,84 & 235,46 & 863,20 & 420,07 \\
\hline $\mathrm{F}$ & Mínimo & $2.105,82$ & $30-40$ & 31,3 & 0 & 410,00 & 160,00 & $1.070,00$ & 210,00 \\
\hline G & Máximo & $2.941,96$ & $40-50$ & 49,6 & 0 & 583,17 & 159,87 & $1.137,47$ & 202,00 \\
\hline $\mathrm{H}$ & Mínimo & $2.209,96$ & $40-50$ & 41,6 & 55 & 430,31 & 178,16 & 878,76 & 443,26 \\
\hline I & Máximo & $2.955,04$ & $50-60$ & 54,3 & 0 & 583,27 & 185,70 & 812,87 & 626,4 \\
\hline $\mathrm{J}$ & Mínimo & $2.623,87$ & $50-60$ & 57,1 & 25 & 515,14 & 185,84 & 972,09 & 411,72 \\
\hline
\end{tabular}




\section{Avaliação do modelo de predição ANFIS}

O modelo preditivo do consumo de energia para diferentes dosagens de concreto convencional foi avaliado por meio do coeficiente de variação (CV), do erro percentual absoluto médio (MAPE) e da raiz quadrada do erro médio (RMSE). Para Amasyali e El-Gohary (2018), essas três medidas são as mais utilizadas na avaliação de modelos de previsão de consumo de energia. Esses parâmetros estatísticos são apresentados respectivamente nas Equações 1, 2 e 3. O modelo também foi avaliado por meio do coeficiente de determinação ( $R$ ), conforme a Equação 4.

$$
\begin{aligned}
& \mathrm{CV}(\%)=\frac{\sqrt{\frac{\sum_{\mathrm{i}=1}^{\mathrm{n}}\left(\mathrm{y}_{\text {predict }, \mathrm{i}}-\mathrm{y}_{\text {data }, \mathrm{i}}\right)^{2}}{\mathrm{n}}}}{\overline{\mathrm{y}}_{\text {data }}} \times 100 \\
& \operatorname{MAPE}(\%)=\frac{1}{n} \sum_{\mathrm{i}=1}^{\mathrm{n}}\left|\frac{\mathrm{y}_{\text {predict }, \mathrm{i}}-\mathrm{y}_{\text {data }, \mathrm{i}}}{\mathrm{y}_{\text {data }, \mathrm{i}}}\right| \times 100 \\
& \operatorname{RMSE}(M J)=\sqrt{\frac{\sum_{\mathrm{i}=1}^{\mathrm{n}}\left(\mathrm{y}_{\text {predict }, \mathrm{i}}-\mathrm{y}_{\text {data }, \mathrm{i}}\right)^{2}}{\mathrm{n}}} \\
& \mathrm{R}^{2}=1-\frac{\sum_{\mathrm{i}=1}^{\mathrm{n}}\left(\mathrm{y}_{\text {predict }, \mathrm{i}}-\mathrm{y}_{\text {data }, \mathrm{i}}\right)^{2}}{\sum_{\mathrm{i}=1}^{\mathrm{n}}\left(\mathrm{y}_{\text {data }, \mathrm{i}}-\overline{\mathrm{y}}_{\text {data }}\right)^{2}}
\end{aligned}
$$

Em que:

$y_{\text {predict, } i}$ é o valor previsto do consumo de energia no instante $i$;

$y_{\text {data, } i}$ é o valor conhecido do consumo de energia no instante $i$; e

$\bar{y}_{\text {data }}$ é a média dos valores conhecidos de consumo de energia do banco de dados, para $n$ dados.

O modelo híbrido ANFIS obtido neste trabalho alcançou resultados significativos, avaliado por meio de CV de $0,0041291 \%$, MAPE de 0,0025834\%, RMSE de 0,1033037MJ e R de 0,9999999, conforme representado na Tabela 6 .

\section{Resultados ANFIS}

O modelo híbrido ANFIS proposto apresentou comportamento adequado e compatível com os dados de treinamento e de validação. Para a representação gráfica foram obtidos diferentes modelos de superfícies fuzzy, e verificaram-se pontos de mínima e máxima energia para diferentes dosagens, em função dos componentes do concreto (Figura 5).

Para a comprovação da eficiência do modelo, este foi avaliado por meio dos parâmetros estatísticos das Equações 1, 2, 3 e 4, respectivamente coeficiente de variação (CV), erro percentual absoluto médio (MAPE), raiz quadrada do erro médio (RMSE) e coeficiente de determinação (R). Nesse processo de validação obteve-se um resultado preciso e acurado, caracterizado por CV de 1,6969\%, MAPE de 0,5792\%, RMSE de 41,8834MJ e R de 0,9771, conforme a Tabela 7.

Os resultados dos parâmetros estatísticos adotados (CV, MAPE, RMSE e R ) apresentaram valores similares aos obtidos por Amasyali e El-Gohary (2018). A convergência das predições pode ser visualizada por meio do parâmetro $\mathrm{R}$ na Figura 6. Os maiores valores de divergência relativa foram encontrados ao simular os dados de Hatem et al. (2012), Gupta (2015) e Ahmed et al. (2016). Essa divergência pode ser devida às diferentes características dos concretos adotados nas distintas pesquisas. Neste caso, observou-se divergência máxima de $12,22 \%$ da predição ANFIS em relação à demanda de energia conhecida do banco de dados.

\section{Consumo de energia}

O requerimento energético total incorporado no concreto, para diferentes dosagens, apresentou resultados com variações absolutas para um mesmo intervalo de resistência mecânica à compressão, de 8.279,25 MJ a 22.914,50 MJ. Os valores correspondem a um valor médio de $24,77 \%$ da demanda total de energia necessária na construção. Os valores de demanda de energia para a construção proposta utilizando as dosagens da Tabela 5 estão representados na Tabela 8. 
Tabela 6 - Desempenho estatístico do modelo ANFIS

\begin{tabular}{c|c|c|c|c}
\hline & CV (\%) & MAPE (\%) & RMSE (MJ) & $\mathbf{R}^{\mathbf{2}}$ \\
\hline ANFIS & 0,0041 & 0,0026 & 0,1033 & 0,9999 \\
\hline
\end{tabular}

Figura 5 - Modelo híbrido de predição ANFIS do consumo de energia para diferentes combinações

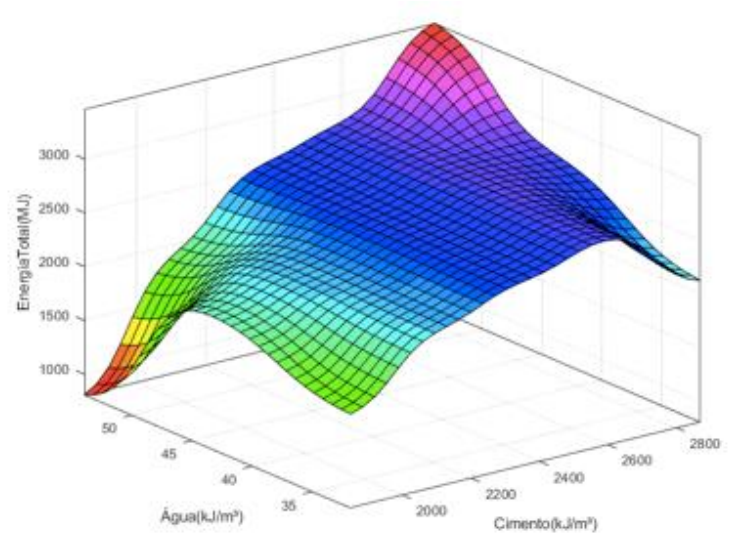

(a) Agua $x$ cimento

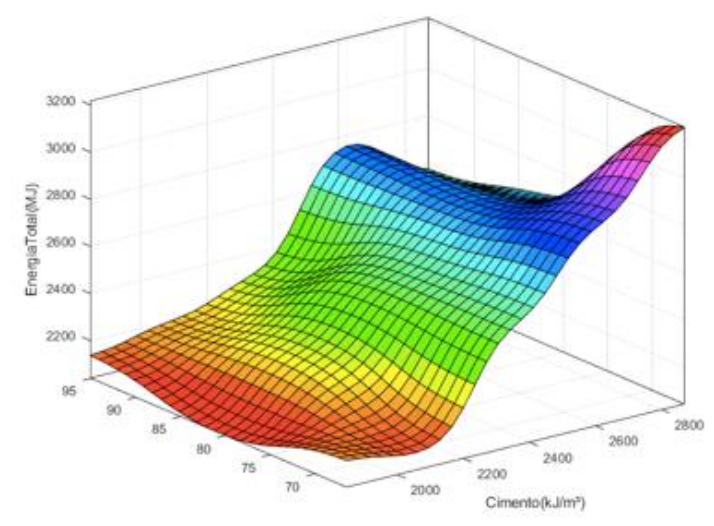

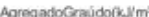

(c) Agregado graúdo x cimento

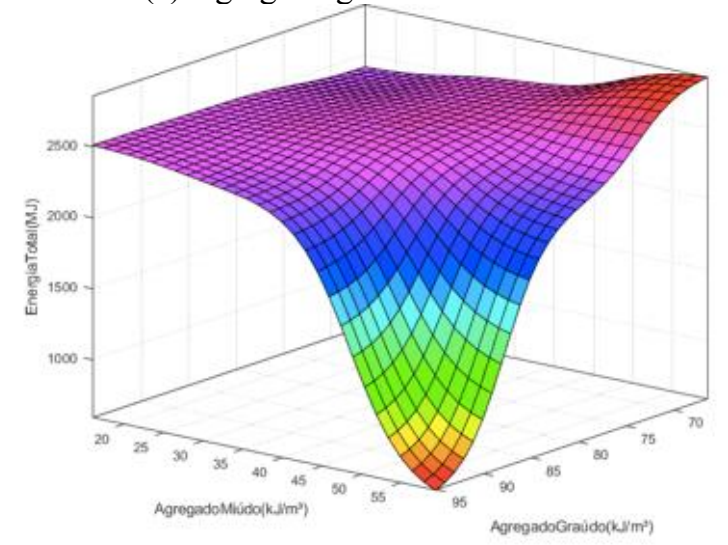

(e) Agregado miúdo x agregado graúdo

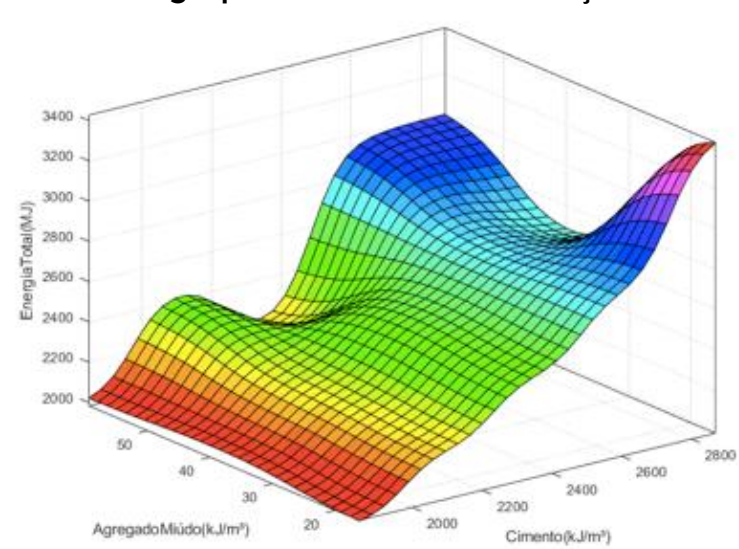

(b) Agregado miúdo x cimento

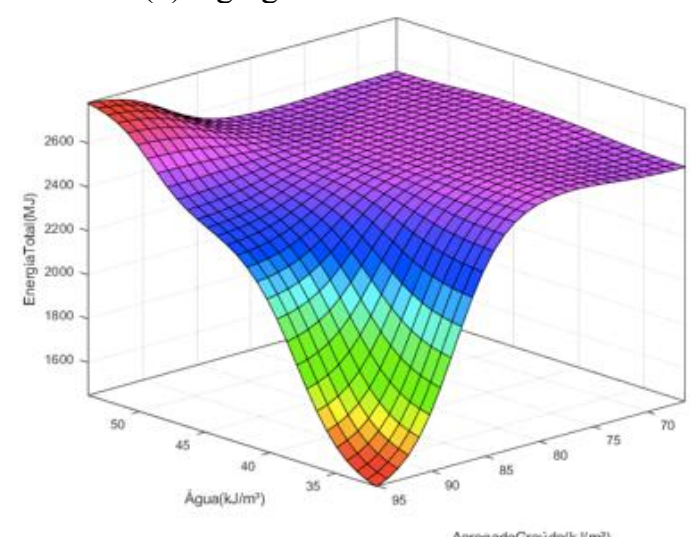

(d) Agregado graúdo x água

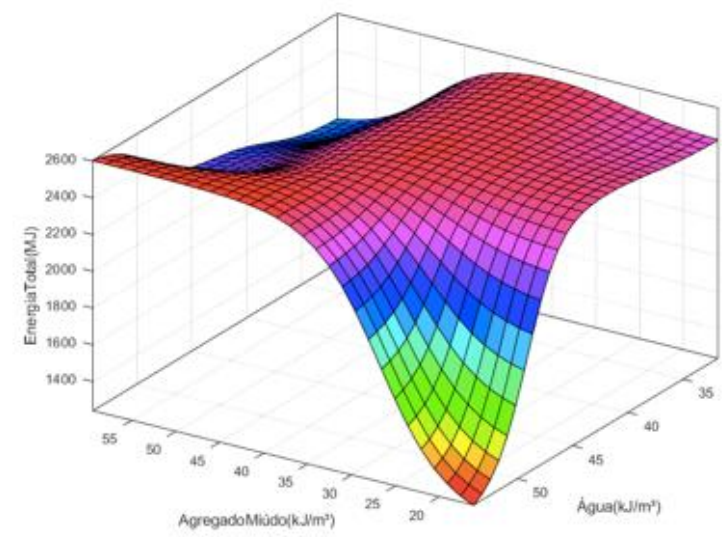

(f) Água x agregado miúdo

Tabela 7 - Validação estatística do modelo ANFIS

\begin{tabular}{c|c|c|l|c}
\hline & CV (\%) & MAPE (\%) & RMSE (MJ) & $\mathbf{R}^{\mathbf{2}}$ \\
\hline ANFIS & 1,6969 & 0,5792 & 41,8834 & 0,9771 \\
\hline
\end{tabular}


Figura 6 - Dispersão de dados reais e previstos pelo ANFIS

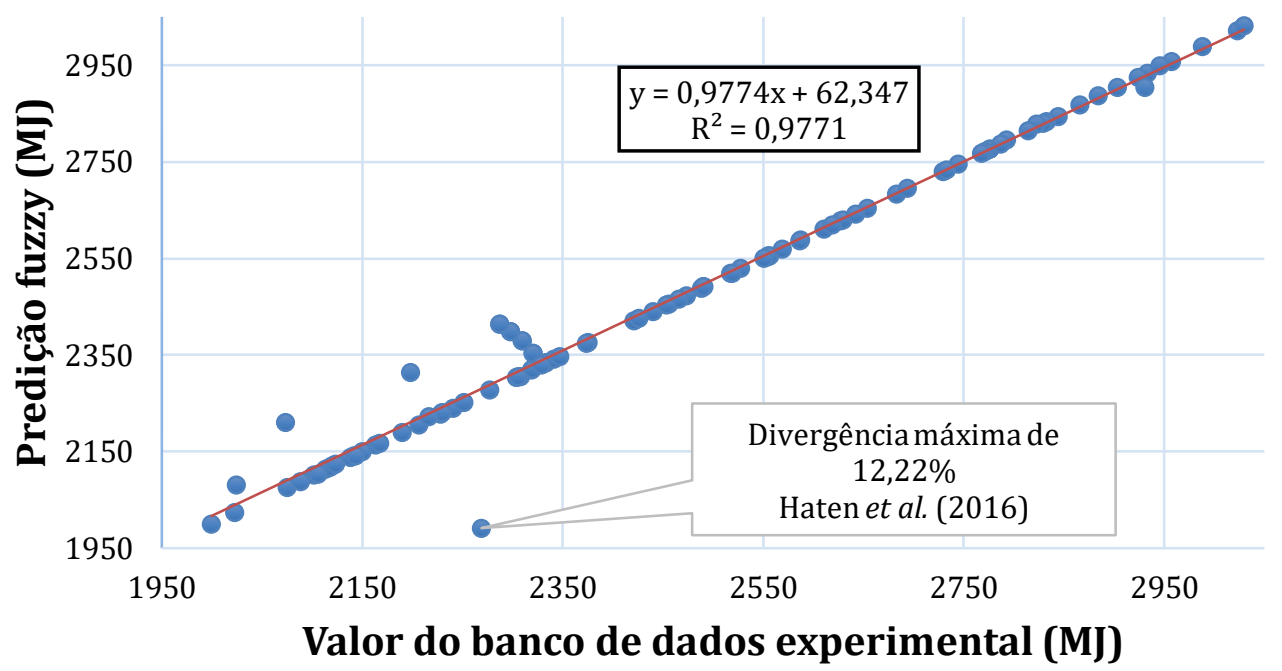

- Predição Fuzzy — Linear (Predição Fuzzy)

Tabela 8 - Demanda total de energia para a construção proposta

\begin{tabular}{c|c|c|c}
\hline $\begin{array}{c}\text { Dosagens } \\
\text { de concreto }\end{array}$ & $\begin{array}{c}\text { Demanda } \\
\text { de energia }\end{array}$ & $\begin{array}{c}\text { Domínio da } \\
\text { variável fc (MPa) }\end{array}$ & $\begin{array}{c}\text { Demanda total de energia } \\
\text { (MJ) para diferentes dosagens }\end{array}$ \\
\hline $\mathrm{A}$ & Máximo & $10-20$ & 70.357 \\
$\mathrm{~B}$ & Mínimo & $10-20$ & 49.984 \\
$\mathrm{C}$ & Máximo & $20-30$ & 75.745 \\
$\mathrm{D}$ & Mínimo & $20-30$ & 54.173 \\
$\mathrm{E}$ & Máximo & $30-40$ & 75.560 \\
$\mathrm{~F}$ & Mínimo & $30-40$ & 52.646 \\
$\mathrm{G}$ & Máximo & $40-50$ & 73.549 \\
$\mathrm{H}$ & Mínimo & $40-50$ & 55.249 \\
$\mathrm{I}$ & Máximo & $50-60$ & 73.876 \\
$\mathrm{~J}$ & Mínimo & $50-60$ & 65.597 \\
\hline
\end{tabular}

O modelo desenvolvido foi capaz de predizer valores da demanda de energia para o intervalo de 10,7 MPa a $57,1 \mathrm{MPa}$ de resistência mecânica à compressão de concretos (estruturais e não estruturais). Observou-se que dosagens com resistência mecânica à compressão entre $10 \mathrm{MPa}$ e $20 \mathrm{MPa}$ podem apresentar uma demanda considerável de energia, o que pode influenciar na escolha de qual dosagem adotar. Esse tipo de concreto não pode ser utilizado para fins estruturais, tendo seu campo de atuação limitado a aplicações sem fins estruturais, conforme importante ressalva da norma NBR 8953 (ABNT, 2015b).

Observou-se que a escolha adequada da dosagem pode influenciar significativamente na sustentabilidade do sistema de produção de concretos. Essa alteração na dosagem também pode gerar economia no custo total da produção de edificações em concreto armado. Observou-se ainda que a demanda de energia na produção do cimento mostrou ser um fator significativo para a demanda total de energia da dosagem, fato esse ratificado por Wang et al. (2017), que pode ser verificado na Figuras 5(a), 5(b) e 5(c).

A escolha da dosagem do concreto pode ainda considerar outros aspectos técnicos, sociais e econômicos, transformando esses diferentes aspectos em indicadores para facilitar comparações entre diferentes alternativas e apoiar a tomada de decisão rápida, conforme relatado por Wang et al. (2017). Fica evidenciada a necessidade da consideração de aspectos técnicos e sociais, além da demanda de energia no projeto de estruturas em concreto armado, sendo a modelagem híbrida (neuro-fuzzy) uma ferramenta que pode ser utilizada na tomada de decisões em projetos com o intuito de avaliar o aporte de energia mínima para a sustentabilidade e o bom desempenho do sistema. Abolpour et al. (2013) ratificaram os resultados obtidos nesta pesquisa ao afirmarem que, devido à complexidade do processo de dosagens em concreto, o uso de modelos baseados em lógica fuzzy pode superar modelagens matemáticas tradicionais (derivação de um

306 Souza, R. M. de; Magalhães, R. R.; Campos, A. T. 
modelo matemático para descrever o sistema), por conseguir trabalhar em cenários difusos e lidar com a relação entre as variáveis de entrada e saída, considerando os parâmetros importantes no processo.

\section{Conclusões}

Esta pesquisa verificou uma alternativa para a avaliação do aporte de energia em diferentes concretos, buscando a eficiência no quesito sustentabilidade do processo de produção do concreto para construções, por meio da avaliação do quantitativo de cada um dos componentes necessários para a produção de concretos convencionais (cimento, água, agregado miúdo e agregado graúdo), utilizando 101 dosagens experimentais distintas.

A proposta deste estudo foi alcançada mediante o desenvolvimento de um modelo híbrido ANFIS, que foi avaliado por meio de parâmetros estatísticos (CV, MAPE, RMSE e R ). O modelo adaptativo neuro-fuzzy apresentou bom desempenho ao predizer dados de energia para diferentes dosagens, caracterizando-se como ferramenta útil para a tomada de decisão em projetos de engenharia.

Conclui-se com este estudo que podem ocorrer variações significativas na demanda de energia total para diferentes dosagens e que essa informação pode ser utilizada para predição de dosagens com menor aporte de energia, com resistência mecânica à compressão de características semelhantes às de maior aporte. Verificou-se ainda que essa alteração pode gerar economia no custo energético das dosagens da ordem de $24,77 \%$ para uma construção convencional em concreto armado.

Por fim, infere-se que o modelo híbrido ANFIS pode ser o aparato necessário para predição e economia energética, deixando o processo de produção de concretos mais sustentável. Ratificou-se com esta pesquisa a necessidade de estudos sobre o balanço energético no processo de produção de concretos ambientalmente sustentáveis, sendo as investigações quase sempre voltadas para a inserção de materiais não convencionais no concreto.

\section{Referências}

ABOLPOUR, B. et al. Estimation of concrete compressive strength by a fuzzy logic model. Research on Chemical Intermediates, v. 39, n. 2, p. 707-719, 2013.

AHMED, M. et al. A comparative study of popular concrete mix design methods from qualitative and costeffective point of view for extreme environment. Arabian Journal for Science and Engineering, v. 41, n. 4, p. 1403-1412, 2016.

AL-GHANDOOR, A. An approach to energy savings and improved environmental impact through restructuring Jordan's transport sector. Renewable and Sustainable Energy Reviews, v. 18, p. 31-42, 2013.

AMASYALI, K.; EL-GOHARY, N. M. A review of data-driven building energy consumption prediction studies. Renewable and Sustainable Energy Reviews, v. 81, p. 1192-1205, 2018.

ASSOCIAÇÃO BRASILEIRA DE NORMAS TÉCNICAS. NBR 12655: concreto de cimento Portland: preparo, controle, recebimento e aceitação: procedimento. Rio de Janeiro, 2015c.

ASSOCIAÇÃO BRASILEIRA DE NORMAS TÉCNICAS. NBR 16697: cimento Portland: requisitos. Rio de Janeiro, 2018.

ASSOCIAÇÃO BRASILEIRA DE NORMAS TÉCNICAS. NBR 5738: concreto: procedimento para moldagem e cura de corpos prova de concreto. Rio de Janeiro, 2015a.

ASSOCIAÇÃO BRASILEIRA DE NORMAS TÉCNICAS. NBR 5739: concreto: ensaio de compressão de corpos de prova cilíndricos. Rio de Janeiro, $2015 \mathrm{~d}$.

ASSOCIAÇÃO BRASILEIRA DE NORMAS TÉCNICAS. NBR 8953: concreto para fins estruturais: classificação pela massa especifica, por grupos de resistência e consistência. Rio de Janeiro, $2015 \mathrm{~b}$.

ASSOCIAÇÃO BRASILEIRA DE NORMAS TÉCNICAS. NBR NM 27: agregados: redução da amostra de campo para ensaios de laboratório. Rio de Janeiro, 2001.

ASSOCIAÇÃO BRASILEIRA DE NORMAS TÉCNICAS. NBR NM 45: agregados: determinação da massa unitária e volume de vazios. Rio de Janeiro, 2006.

ASSOCIAÇÃO BRASILEIRA DE NORMAS TÉCNICAS. NBR NM 52: agregado miúdo: determinação da massa específica e massa específica aparente. Rio de Janeiro, 2009a. 
ASSOCIAÇÃO BRASILEIRA DE NORMAS TÉCNICAS. NBR NM 53: agregado graúdo: determinação da massa específica, massa específica unitária e absorção de água. Rio de Janeiro, $2009 \mathrm{~b}$.

ASSOCIAÇÃO BRASILEIRA DE NORMAS TÉCNICAS. NBR NM 67: concreto: determinação da consistência pelo abatimento do tronco de cone. Rio de Janeiro, 1998.

BORGES, P. H. R. et al. Estudo comparativo da análise de ciclo de vida de concretos geopoliméricos e de concretos à base de cimento Portland composto (CP II). Ambiente Construído, Porto Alegre, v. 14, n. 2, p. 153-168, abr./jun. 2014.

CAMPOS, A. T. et al. Custo energético de construção de uma instalação para armazenagem de feno. Ciência Rural, Santa Maria, v. 33, n. 4, p. 667-672, 2003.

DE SOUZA, R. M.; MAGALHÃES, R. R.; DE ANDRADE, E. T. Comparative study of non-linear simulations of a reinforced concrete slender column using finite element method and p-delta. Theoretical and Applied Engineering, v. 3, n. 1, p. 1-11, 2019.

DEB, C. et al. A review on time series forecasting techniques for building energy consumption. Renewable and Sustainable Energy Reviews, v. 74, p. 902-924, 2017.

GONG, X. et al. Life cycle energy consumption and carbon dioxide emission of residential building designs in beijing. Journal of Industrial Ecology, v. 16, p. 576-587, 2012.

GUPTA, S. Use of triangular membership function for prediction of compressive strength of concrete containing nano-silica. Cogent Engineering, v. 2, n. 1, p. 1025578, 2015.

HATEM, M. et al. Design of concrete mixes by systematic steps and ANN. Journal of Advanced Science and Engineering Research, v. 2, n. 4, p. 232-251, 2012.

KNOERI, C.; SANYÉ-MENGUAL, E.; ALTHAUS, H.-J. Comparative LCA of recycled and conventional concrete for structural applications. The International Journal of Life Cycle Assessment, v. 18, n. 5, p. 909-918, 2013.

LI, K.; SU, H.; CHU, J. Forecasting building energy consumption using neural networks and hybrid neurofuzzy system: a comparative study. Energy and Buildings, v. 43, n. 10, p. 2893-2899, 2011.

MATTIOLI, M. C. et al. Demanda energética na construção de galpão para frangos de corte modelo Darkhouse. Energia na Agricultura, Botucatu, v. 33, n. 3, p. 216-223, 2018.

MEHTA, P. K.; MONTEIRO, P. J. M. Concreto: microestrutura, propriedades e materiais. 2. ed. São Paulo: Ibracon, 2014.

MITHUN, B. M.; NARASIMHAN, M. C. Performance of alkali activated slag concrete mixes incorporating copper slag as fine aggregate. Journal of Cleaner Production, v. 112, p. 837-844, 2015.

MOUSAVI-AVVAL, S. H. et al. Combined application of life cycle assessment and adaptive neuro-fuzzy inference system for modeling energy and environmental emissions of oilseed production. Renewable and Sustainable Energy Reviews, v. 78, p. 807-820, 2017.

NABAVI-PELESARAEI, A. et al. Integration of artificial intelligence methods and life cycle assessment to predict energy output and environmental impacts of paddy production. Science of the Total Environment, v. 631-673, p. 1279-1294, 2018.

NAJI, S. et al. Application of adaptive neuro-fuzzy methodology for estimating building energy consumption. Renewable and Sustainable Energy Reviews, v. 53, 1520-1528, 2016.

OLATOMIWA, L. et al. Adaptive neuro-fuzzy approach for solar radiation prediction in Nigeria. Renewable and Sustainable Energy Reviews, v. 51, p. 1784-1791, 2015.

SANTOS, A. G.; FERRARI, A. K. Influência do resíduo de PVC como agregado no concreto para peças de pavimentos intertravados. Ambiente Construído, Porto Alegre, v. 19, n. 3, p. 39-51, jul./set. 2019.

SANTOS, R. S. Energia incorporada na fase de pré-uso: comparação entre lajes steel deck e maciças.

Ambiente Construído, Porto Alegre, v. 19, n. 3, p. 197-205, jul./set. 2019.

SHAIKH, P. H. et al. A review on optimized control systems for building energy and comfort management of smart sustainable buildings. Renewable and Sustainable Energy Reviews, v. 34, p. 409-429, 2014.

SHAMSHIRBAND, S. et al. Heat load prediction in district heating systems with adaptive neuro-fuzzy method. Renewable and Sustainable Energy Reviews, v. 48, p. 760-767, 2015. 
WANG, J. et al. Life cycle sustainability assessment of fly ash concrete structures. Renewable and Sustainable Energy Reviews, v. 80, p. 1162-1174, 2017.

ZHANG, Z. Y.; WANG, B. Hybrid input-output analysis for life-cycle energy consumption and carbon emissions of China's building sector. Building and Environment, v. 104, p, 188-197, 2016.

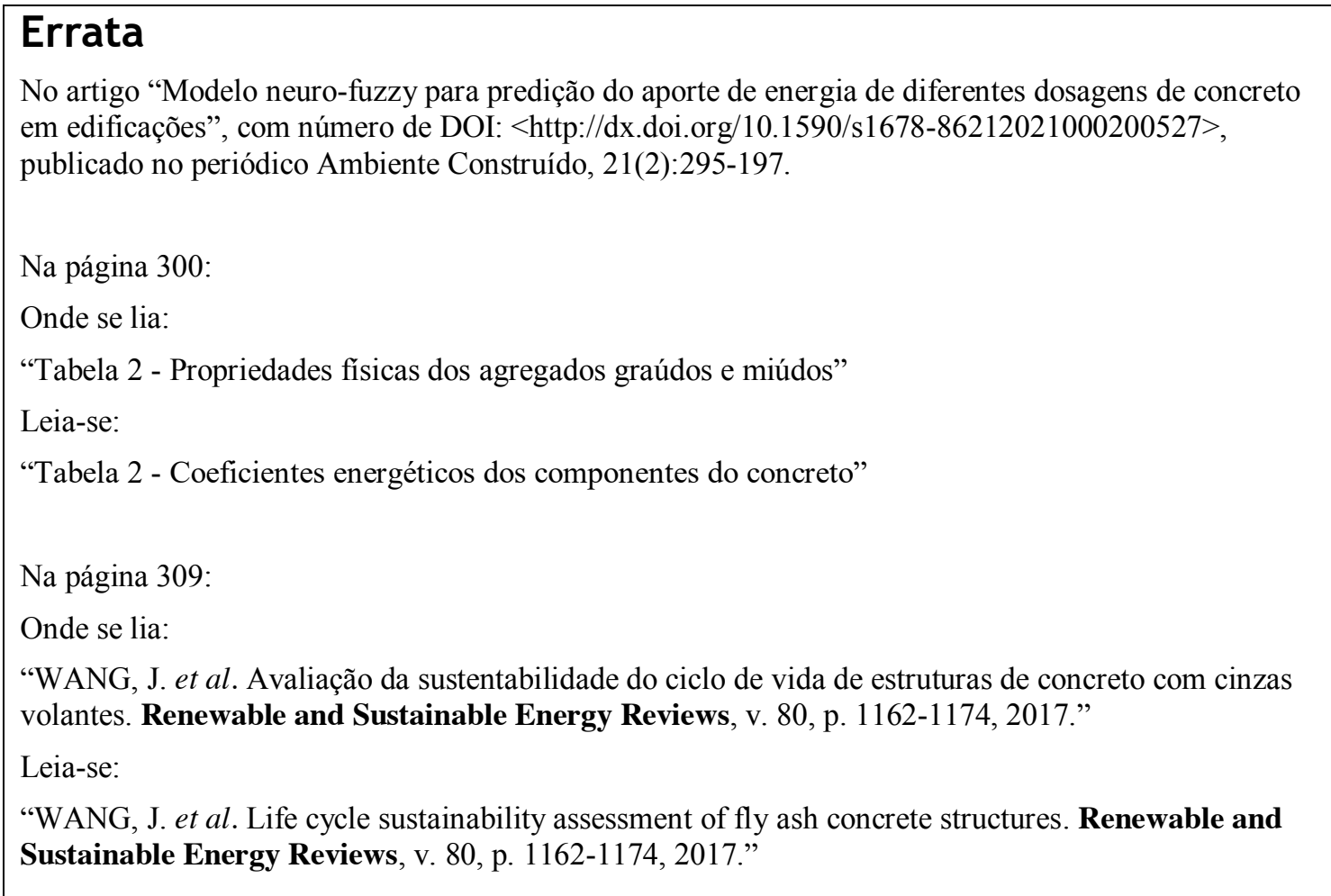

Régis Marciano de Souza

Departamento de Engenharia Civil | Instituto Federal de Educação, Ciência e Tecnologia do Sul de Minas | Av. Maria da Conceição Santos, 900, Parque Real, Campus Pouso Alegre | Pouso Alegre - MG -Brasil | CEP 37550-000 | Tel.: (35) 3427-6600 | E-mail: regis.souza@ifsuldeminas.edu.br

\section{Ricardo Rodrigues Magalhães}

Departamento de Automática| Universidade Federal de Lavras | Av. Sul, s/n, Aquenta Sol | Lavras - MG - Brasil | CEP $37200-900$ | Tel.: (35) 3829-5234 | E-mail: ricardorm@ufla.br

\section{Alessandro Torres Campos}

Departamento de Engenharia Agrícola | Universidade Federal de Lavras | Lavras - MG - Brasil | Caixa Postal 3037 | CEP $37200-900$ | Tel.: (35) 3829-1486 | E-mail: campos@ufla.br

\section{Ambiente Construído}

Revista da Associação Nacional de Tecnologia do Ambiente Construído

Av. Osvaldo Aranha, $99-3^{\circ}$ andar, Centro

Porto Alegre - RS - Brasil

CEP 90035-190

Telefone: +55 (51) 3308-4084

Fax: +55 (51) 3308-4054

www.seer.ufrgs.br/ambienteconstruido

E-mail: ambienteconstruido@ufrgs.br

This is an open-access article distributed under the terms of the Creative Commons Attribution License. 